\title{
Safety and Security of Sexual-reproductive Health and Gender-based Violence among Rohingya Refugee Women in Bangladesh
}

\author{
Rabeya Yousuff, Md. Mushtahid Salam², Shaima Akter ${ }^{3}$, Abdus Salam $^{4}$
}

\begin{abstract}
$\underline{\text { Abstract }}$
Rohingya refugee women and girls are from a vulnerable society taking shelter in Bangladesh for humanitarian assistance following the serious human rights violations in Myanmar. They are facing a number of challenges such as insecurity, violence, very limited freedom of movement or ability to speak up and influence decisions in their communities. They are most vulnerable to exploitation due to inadequate basic living facilities in the camp causing them to be physically or sexually abused, forced prostitution and human trafficking. Gender-based violence, abandonment by their husbands in the camps, early marriage, teenage pregnancies including lack of safer pregnancy and childbirth are all important issues and challenges faced by them. Access to basic amenities and educational opportunities with special attention about sexual and reproductive health including issues such as gender equality, relationships and conflict management and adequate community health care can help the Rohingya women to overcome the situation. Actually, the word "Rohingya" derived from the people who exist in from the British rule of the medieval period in the current "Rakhine" state, formerly known as "Roshang" later turned into "Rohang" due to colloquial usage. Although officially Myanmar is not using the term "Rohingya" as this might potentially endorse their indigenous origin, an international involvement is obligatory to find a solution for sustainable return of Rohingya refugees to Myanmar.

Kevwords: Safety, Rohingya refugee, women, sexual-reproductive health, gender-based violence.
\end{abstract}

International Journal of Human and Health Sciences Vol. 05 No. 02 April'21 Page : 163-170 DOI: http://dx.doi.org/10.31344/ijhhs.v5i2.254

\section{Introduction}

Rohingya are the Muslim community living in Rakhine state of Western Myanmar who are officially stateless and disowned by the Myanmar government as the 1982 Citizenship Law took away their Myanmar citizenship and forced them to face severe humanitarian crisis. They differ in language, appearance, and religion from Myanmar's dominant Buddhist population ${ }^{1,2}$. They are forced to take migration to the neighboring countries of Thailand, Bangladesh and Malaysia due to religious and geographical factors ${ }^{3}$. In Bangladesh, this forced migration of the Rohingya population took place as early as 1978, and again in 1991-1992 due to the torture by Myanmar security forces including rape, arrests, and executions. This forced migration causes total displacement of almost 250,000 people during these two occasions ${ }^{4}$. Those who left in Myanmar, faced anti-Muslim riots in 2001 and later violence

1. Blood Bank Unit, Department of Diagnostic Laboratory Services, Universiti Kebangsaan Malaysia Medical Centre (UKMMC), Cheras, Kuala Lumpur, Malaysia.

2. Department of Social and Preventive Medicine, Faculty of Medicine, University of Malaya, Kuala Lumpur, Malaysia.

3. Department of Medicine, Faculty of Medicine, Chittagong Medical College \& Hospital, Chittagong, Bangladesh.

4. Medical Education Unit, Faculty of Medicine, Widad University College, Kuantan, Pahang, Malaysia.

Correspondence to: Dr. Abdus Salam, Associate Professor and Head of Medical Education Unit, Faculty of Medicine, Widad University College, Kuantan, Pahang, Malaysia. E-mail: abdussalam.dr@gmail.com, ORCID ID: 0000-0002-2629-4903. 
between Rohingya Muslims and Arakanese Buddhists in Rakhine State causes deaths and demolition of their property leading to another mass displacement in 2012. Most recent displacement occurred in October 2016 when Rohingya armed group namely the Arakan Rohingya Salvation Army (ARSA) attacked and killed nine police officers causing the Myanmar military to respond with a major security operation which is marked as human rights violations ${ }^{4}$. After that incidence, the largest influx of Rohingya refugee population of over 900,000 fled to Bangladesh for humanitarian assistance 5,6 . One report states that, till April 2019 approximately total 911,359 Rohingya refugees took shelter in Cox's Bazar including 34,172 refugees who were registered before 31 st August $2017^{7}$. The vast majority of the Rohingya population are living in total 34 camps and the largest camp is the Kutupalong-Balukhali Expansion Site that hosts approximately 626,500 Rohingya $^{8,9}$.

Among the total number of Rohingya, approximately $52 \%$ are women and girls ${ }^{10}$. In another report by UNICEF, mentioned that $67 \%$ of the refugees are female which accounts to 335,670 female refugees ${ }^{11}$. Many of the women are alone with their children and bearing the responsibility of their family ${ }^{12}$. It is estimated that $16 \%$ of the total number of Rohingya refugee households in Bangladesh are female headed ${ }^{13}$.Bangladesh Government has provided shelter for them and also other basic requirements such as food, clean water, health facility and other necessary things with the help from the humanitarian world and the people of Bangladesh. In Myanmar, they have been exposed to persistent persecution and conflict. Comparing to that situation, they feel that their life is better in Bangladesh than that in Myanmar. However, the displaced Rohingya refugees still faces numerous challenges in the camp life. The challenges faced by the women and girls are different from that of the male population. They face challenges concerning the safety and security issues, sexual and reproductive health (SRH) issues including safer pregnancy and childbirth, marriage practices, gender-based violence (GBV), and other related issues. The objective of this article is to review the issues, challenges faced by the Rohingya women and girls in their camp accommodation and the steps taken to improve the situations.

\section{Rohingya Women}

The Rohingya are a conservative community, with social and cultural norms that restricts women's empowerment. Women generally experience barriers to freedom of movement when they reach puberty. They are confined to the home and restricted to come to the public places. They also have restricted access to and control over resources ${ }^{14}$. Thus they faced double restrictions in their homeland due to limitations imposed by their government and military during their stay in Myanmar and also from the men in their community. Previous study on 3000 Rohingya refugees showed that $94 \%$ women did not play any role about their consent in their marriage, and that $45 \%$ were married as children. Again, $95 \%$ of them reported that the main role of women is cooking; 53\% women believed that they should not be allowed to leave the house and $42 \%$ of them reported spending an average of 21-24 hours/ day inside their house. Thus their mobility, leadership skill, decision-making capability are all hindered that can have a negative impact on their lives ${ }^{10}$. Being grown up in such a situation and displaced from country of origin to a refugee status in different country, their situation becomes terribly challenging.

\section{Issues and challenges related to safety and security}

The Rohingya refugee women faces challenges such as insecurity, violence, very limited freedom of movement or ability to speak up and influence decisions in their communities ${ }^{12}$. Families headed by female and elderly persons with no male relatives suffered greater vulnerability than those families with adult males. Because of the economic compulsion in the new camp situation, they cannot be confined to the house. They need to accomplish a huge number of difficult tasks for their families such as cooking, collecting water, monsoonproofing their huts, fixing roofs, breastfeeding, chopping and carrying firewood, and collecting rations $\operatorname{etc}^{15}$. These single women or single mothers in addition to cope alone in the refugee camps, experiences access barriers to humanitarian relief services for food, shelter and other issues ${ }^{10}$. They are reported of being harassed while performing essential tasks, such as collecting water, using the latrine or feelings of 'shame' around using water, sanitation and hygiene (WASH) facilities ${ }^{16,17}$. Difference in spoken language prevent them from getting specific healthcare needs and other humanitarian assistance ${ }^{18}$. The barriers from leaving their shelters also includes the cultural respect for the practice of purdah, fears around safety, the burden of care work for the family, lack of public lighting, lack of appropriate clothing and 
lack of women-only spaces ${ }^{17}$. The safety issue is so significant that they are under a constant risk of rape while leaving their shelter for their daily work and especially at night while using the latrines ${ }^{19}$. Sexual and reproductive health (SRH) issues

Rohingya women and girls are most vulnerable to exploitation in terms of SRH issues due to inadequate basic living facilities in the camp. They are reported to be physically or sexually abused, or even faced forced prostitution ${ }^{20}$. In the camp, lack of income generating activities leads the women and adolescent girls to increased risk of exploitation in the form of trafficking for commercial sexual purposes, forced marriages and forced labor ${ }^{21}$. Child marriage is a preference for them in absence of well-defined laws regarding minimum age at marriage and legal documentation processes for marriage registration in the camps ${ }^{22}$.These are considered as a negative coping mechanism to ease economic and food insecurity ${ }^{20,21}$. Even they are reported to take part in illegal drug business ${ }^{21}$ which together with the illegal sex increases the risk of exposure to sexually transmitted infection among the Rohingya women and young girls ${ }^{18}$.

They are most vulnerable to human trafficking both inside and outside the country following the pattern of trafficking globally ${ }^{20}$. There are criminal syndicates has been grown up to exploit the women in the refugee camps and trafficking them to Malaysia through unsafe boats. They are actively luring Rohingya women to go to Malaysia from various camps in Bangladesh. They convince women to go to Malaysia to marry Rohingya men in Malaysia and thus to get rid of the poverty they are suffering from in the camp. They even ensure them of getting some kind of work which in turn can help their families too ${ }^{23}$.

Safer pregnancy and childbirth are of great concern among the Rohingya refugees, although, maternal health care facility is available in the camp ${ }^{24}$. It is reported that in the camp's overstretched health-care facilities, 24,000 pregnant and lactating Rohingya women require maternal health-care support $^{10}$. The social, cultural, and historical context influences their views on childbearing, family planning, and contraception. They do not willingly go to the health care services for childbirth due to ignorance or prevented by their husband or mother in law who are the important decision maker regarding the attendance to the health care facility. Therefore, home delivery using traditional birth attendants is preferable to them even though currently they are residing in the camp environment. Family planning or use of contraception is not practiced by them due to the preference for large family and also for the religious beliefs and stigma and misconceptions about contraception ${ }^{24}$.

Their ignorance about the HIV/AIDS or other sexually transmitted infections due to lack of education and health services opportunity that they received while residing in Myanmar makes them more susceptible to such diseases ${ }^{22}$. Currently although sexual and reproductive health services are provided at the refugee camps giving priority to the lifesaving activities, still it is a major issue for access to essential comprehensive reproductive, maternal and newborn health service due to the societal norms and cultures as well ${ }^{1}$. It is very important to teach them about sexual and reproductive health and well-being and issues such as gender equality, pubertal changes and hygiene, relationships and conflict management ${ }^{24}$.

\section{Gender-based violence}

Gender-based violence (GBV) is the human rights violation protected by international human rights conventions ${ }^{25}$. Both women and men experience GBV but in a broad term, it identifies the violence against women and girls whether it is committed through sexual violence or through other means. Gender-based violence includes domestic violence, sexual harassment, sexual violence and rape $^{26}$. Most of the cases of GBV are sexual, and GBV the victims are female, while the perpetrators are male ${ }^{27}$.

It is assumed that they have been exposed to sexual violence at all three stages which are during their stay in Rakhine State, during flight and during their refugee status in the refugee camps in Bangladesh ${ }^{27}$. Rohingya women and girls' experiences on GBV including rape and sexual assault by the Myanmar army are for a long decade although, many victims do not like to report their ordeal out of concerns over safety, confidentiality, shame and stigma ${ }^{28}$. Many of the survivors of the serious human rights violations in Myanmar reported sexual violence such as sexual assault, rape and gang rape ${ }^{29}$. There was no immediate service provided to the rape survivors in Myanmar such as access to urgent interventions, like emergency contraception (120 hours) and prophylaxis against HIV infection (72 hours). The Myanmar government obstructs the humanitarian access to Rakhine State ${ }^{30}$. Many rape cases have resulted in pregnancy leading to unsafe abortion ${ }^{31}$. 
It is estimated that at least $2.6 \%$ of those assaulted by sexual violence succumbed to death ${ }^{32}$. The survivors are susceptible to contract sexually transmitted diseases ${ }^{18}$. The United Nations Population Fund (UNFPA) reported that since late August 2017 they have assisted 3500 sexually assaulted Rohingya women ${ }^{16}$. Based on $6 \%$ reporting rate of the rape victims to the UNFPA, it is estimated around 58,300 Rohingya women and girls experienced sexual violence ${ }^{11}$.

In Bangladesh, with the current refugee status, Rohingya women are more vulnerable to domestic and community violence due to breakdown in social norms, disruption of the family structure ${ }^{27}$. UNCHR (2003) identifies that unequal power relationships as an underlying reason for GBV in the refugee camps in Cox Bazar area. The perpetrators who commit sexual assaults and harassment belongs either from their own community men or men from the host community such from the villagers or from camp itself including security personne ${ }^{27,33}$. In a report by UNFPA in August 2018, over 10,000 incidents of GBV were reported since past one year ${ }^{16}$. Ignorance about the gender equality and rights makes them vulnerable towards facing domestic violence either from the husband or other family members or from community ${ }^{24}$. Rohingya women and girls enters a vicious cycle of social disease of GBV and leading a life without any access to the fundamental rights due to the consequences of lack of education, low income generation, lack of access to adequate healthcare, increased vulnerability to trafficking and forced prostitution, early marriage, teenage pregnancies and poor quality of living ${ }^{34}$. Abandonment by their husbands in the camps is a new emerging issue for the Rohingya women. The husbands are leaving their wife and even children either to escape beyond the Rohingya settlements into other parts of Bangladesh, or to get marry another woman in the camp. As no marriage registration is necessary, polygamy becomes a common trend in the refugee camp $^{15}$.

\section{Humanitarian assistance}

Bangladesh government is giving assistance to the Rohingya refugees in their humanitarian crisis with the help of United Nations High Commissioner for Refugees (UNHCR), and other national and international non-government organizations (NGOs). There are 130 nongovernment organizations (NGOs) working in the Cox's Bazar area including at least 13 local, 45 national and 69 international NGOs, the Red
Cross/Red Crescent Movement, and $12 \mathrm{UN}$ agencies as of February $2018^{35}$. Health sector partners provides services through Health Post, Health Centre and Hospitals including static and mobile facilities in all camps. The active working groups acts on Mental Health and Psychosocial Support (MHPSS), Sexual and Reproductive Health (SRH), Community Health, Health Sector Emergency Preparedness and Response, Acute Watery Diarrhoea and Vector-borne Diseases ${ }^{36}$. In partnership with the World Health Organization (WHO) and United Nations High Commission for Refugees (UNHCR), Malaysian Field Hospital (MFH), Turkish Field Hospital, Medicins Sans Frontieres (MSF), International Federation of Red Cross and Red Crescent Societies (IFRC), BRAC, International Organization for Migration (IOM), Save the Children,Action Against Hunger and HOPE hospital,has been involved in providing the health services in the camp ${ }^{37,38,39,40}$. Local NGO together the religious institutions provide the relief work and other basic services and international NGOs are delivering services such as relief, water, sanitation and hygiene (WASH), training, protection, shelter and other activities as per requirement of the government ${ }^{35}$.

In order to strengthen SRH services to Rohingya refugees, Inter-Agency Working Group (IAWG) on Reproductive Health in Crisis are working to increase the provision and access to the Minimum Initial Service Package (MISP).The IAWG is currently controlled by a steering committee of 12 agencies from representatives of $\mathrm{UN}$ agencies, national and international non-governmental organizations (NGOs) and academic organizations. The MISP for Reproductive Health (RH) was first articulated in 1996 to provide basic reproductive health services during the first phase of an emergency. MISP includes the set of activities to prevent and manage the consequences of sexual violence, to reduce HIV transmission, to prevent excess maternal and newborn morbidity and mortality, and plan for comprehensive reproductive health services ${ }^{4,41-43}$.

UNFPA is a leading organization works through the United Nations, international and local nongovernmental organizations, and government agencies to provide sexual, reproductive and maternal health care services and also work for GBV. They had established 18 women friendly spaces in the refugee camps and two in the host community which are called as "shanti khana" or homes of peace by the Rohingya refugees. 
UNFPA supports safe spaces to provide medical, psychosocial, and legal services for survivors of GBV including post-rape care. They provide voluntary family planning at safe spaces, prenatal and delivery care through midwives, provide thousands of dignity kits which include menstrual hygiene supplies, soap, clothes, a flashlight and a whistle to help women move around more freely and confidently. Women and girls also able to get trainings on sewing and to earn money from their work $^{4}$. UNFPA has arranged the training and skill center for midwives for the provision of care to the pregnant women ${ }^{4}$.

In spite of the services provided by the Government and international organizations, still there are concerns about safety and security and other issues. There are many challenges such as high rate of home delivery, insufficient health clinics, access to voluntary contraception, HIV/STI treatment, and comprehensive post-rape care. A number of factors are responsible to act as a barrier such as limited mobility aggravated by monsoon season, lack of awareness, cultural barriers, and even opposition from family by husbands ${ }^{43}$.It is required to pay more attention towards the SRH of the large number of Rohingya women and girls $^{43}$. One survey in March 2018 showed that $56.6 \%$ pregnant mother received no antenatal care, and $73.7 \%$ pregnant lady delivered at home without a certified birth attendant ${ }^{44}$. Another report by 2019 Joint Response Plan describes, only 43\% of minimum service coverage has been achieved for urgently required GBV case management and psychosocial support (PSS)for children and adults till November $2018^{8}$. They reported, out of 34 camps, four are still not covered by essential minimum GBV services such as case management, access to psychosocial support health, clinical management of rape (CMR), legal counselling and safe spaces for women and girls while five camps only have $25-50 \%$ of GBV service ${ }^{8}$.

The origin of the word "Rohingi' or "Rohingya" comes from the people who exist in, from the British rule of the medieval period in the current "Rakhine" state, formerly known as "Roshang" state later turned into "Rohang" due to colloquial usage; Myanmar even has an official policy of not using the term "Rohingya", as this might potentially endorse the indigenous origin of the community which currently make up the largest stateless community in the world ${ }^{45}$. The injustice imposed to the refugees by violating the human rights would create a deep wound in humanity. The world needs to understand that the refugees have similar needs with other people and equal rights to meet those needs ${ }^{46}$. An international involvement is necessary to find a solution for sustainable return of Rohingya refugees to Myanmar.

\section{Recommendation}

Rohingya women and girls have suffered many years of oppression and deprivation of basic services, should have a basic level of safety and security ${ }^{30}$.Policy makers are required to pay special attention to overcome the challenges and ensure optimal care and rehabilitation of them. A strong emphasis should be given on the basic need such as food, water, health, sanitation, shelter and protection and the special needs of women, girls, including safer pregnancy and childbirth; the prevention of and response to GBV; and education and life skills for children and youth who will, in all probability, become adults in the camps of Cox's Bazar ${ }^{24}$. It is necessary to find a solution for safe, dignified, voluntary and sustainable return of refugees to Myanmar. An international involvement and a long-term plan for their future rehabilitation and establishment in their own country is very much needed.

\section{Conclusions}

This review highlights the issues and challenges related to safety, sexual health, GBV among Rohingya refugee women in Bangladesh. It is essential to take steps for: i) adequate security by strengthening law enforcement; ii) access to basic amenities; iii) educational opportunities with special attention about sexual and reproductive health including issues such as gender equality, relationships and conflict management; iv) adequate community health care and SRH services with female trained staff having language proficiency; iv) skill based training programs such as sewing, embroidery, preparing handicrafts etc. that can allow them to earn to help their family. v) Finally, an international involvement and a long-term plan for their future rehabilitation and establishment in their own country is very much needed.

Conflict of Interest: We declare that there is no financial or other conflict of interest.

Funding: Not related.

Ethical Approval Issue: Not applicable. 


\section{References:}

1. Ahmed R, Farnaz N, Aktar B, Hassan R, Shafique SB, Rayet P. et al. Situation analysis for delivering integrated comprehensive sexual and reproductive health services in humanitarian crisis condition for Rohingya refugees in Cox's Bazar, Bangladesh: protocol for a mixed-method study. BMJ Open 2019;9:e028340.

2. Prodip MA. Health and Educational Status of Rohingya Refugee Children in Bangladesh. Journal of Population and Social Studies, 2017;25(2):135-46.

3. Letchamanan H. Myanmar's Rohingya Refugees in Malaysia: Education and the Way Forward. Journal of International and Comparative Education (JICE) 2013;2(2):8697.

4. Goodman A, Mahmood I. The Rohingya Refugee Crisis of Bangladesh: Gender Based Violence and the Humanitarian Response. Open Journal of Political Science 2019; 9:490-501.

5. UNHCR. BANGLADESH REFUGEE EMERGENCY Population factsheet. (2019). https://data2.unhcr.org/en/documents/ download/69954. Accessed19 June 2019.

6. Huzairi S, Nada SZ. Scarred Heart: A Case Series. International Journal of Human and Health Sciences 2019; Supplementary Issue: S56.

7. ISCG, Inter Sector Coordination Group. Situation Report: Rohingya Refugee Crisis, Cox's Bazar. 2019.https://reliefweb.int/ sites/reliefweb.int/files/resources/sitrep april_2019.pdf. Accessed24 February 2020.

8. 2019 Joint Response Plan JANUARYDECEMBER. 2019.https://reliefweb.int/ report/bangladesh/2019-joint-responseplan-rohingya-humanitarian-crisis-januarydecember-enbn_Accessed: 22 February 2020.

9. Hassan JA. The Dust of Kutupalong. International Journal of Human and Health Sciences 2018; 2 (3):176-181. https:// ijhhsfimaweb.info/index.php/IJHHS/article/ view/52..doi:http://dx.doi.org/10.31344/ijhhs. v2i3.52.Accessed 29 July 2020.

10. UN Women. Gender Brief on Rohingya Refugee Crisis Response in Bangladesh. UN Women Bangladesh. 2018. https:// www2.unwomen.org/-/media/field $\% 20$ office $\% 20$ eseasia/docs/publications/2017/10/ gender-advocacy-paper-for-rohingya- refugee-crisis-response-in-bangladesh-r10. pdf?la $=$ en\&vs $=2521$. Accessed 3 October 2019.

11. Hutchinson S. Gendered insecurity in the Rohingya crisis. Australian Journal of International Affairs 2017;72(1):1-9.

12. Oxfam. Breaking barriers for Rohingya refugee women. Relief web. 2018. https:// reliefweb.int/report/bangladesh/breakingbarriers-rohingya-refugee-women. Accessed 19 June 2019.

13. Gaynor T. Rohingya widows worry about their families' futures. UNHCR 2018.https://www. unhcr.org/news/stories/2018/4/5ad494934/ rohingya-widows-worry-families-futures. html. Accessed 19 June 2019.

14. Joint Agency Research Report. Rohingya Refugee Response Gender Analysis, Recognizing and responding to gender inequalities. 2018. https://reliefweb.int/sites/ reliefweb.int/files/resources/rr-rohingyarefugee-response-gender-analysis-010818-en. pdf Accessed 3 October 2019.

15. Nianias H. Our men are leaving us': the Rohingya women facing life alone. The Guardian, 2018. https://www.theguardian. com/global-development/2018/jun/28/ourmen-are-leaving-us-the-rohingya-womenfacing-life-alone Accessed 19 June 2019.

16. Learson C. One year on, Rohingya women and girls seek safety - and a chance to heal. UNFPA. 2018. https://www.unfpa.org/ news/one-year-rohingya-women-and-girlsseek-safety-\%E2\%80\%93-and-chance-heal. Accessed 2 October 2019.

17. Sang D. One year on Time to Put Women and Girls at the Heart of the Rohingya Response. Oxfam. 2018. https://www.oxfamamerica.org/ static/media/files/bp-one-year-on-rohingyarefugee-women-girls-110918-en.pdf. Accessed 2 October 2019.

18. Hossain MM, Sultana A, Mazumder H, MunzurE-Murshid. Sexually transmitted infections among Rohingya refugees in Bangladesh. The Lancet HIV 2018a:5(7):PE342.

19. Riley A, Varner A, Ventevogel P, Hasan T. Daily Stressors, Trauma Exposure, and Mental Health among Stateless Rohingya Refugees in Bangladesh. Transcultural Psychiatry 2017; 54:304-331.

20. United Nations (UN). UN warns of trafficking, sexual abuse in shadow of Rohingya refugee crisis. UN News. 2017a. https://news. 
un.org/en/story/2017/11/636002-un-warnstrafficking-sexual-abuse-shadow-rohingyarefugee-crisis. Accessed 2 October 2019.

21. Gordon E, Lee-Koo K, Jay H. Adolescent Girls in Crisis: Voices of the Rohingya. Plan International, United Kingdom. 2018 .https://plan-uk.org/file/planuk-voices-of-the-rohingya-reportpdf/ download?token=BS11dYzS. Accessed 14 July 2019.

22. Ainul S, Ehsan I, Haque EF, Amin S, Rob $\mathrm{U}$, Melnikas AJ, Falcone J. Marriage and sexual and reproductive health of Rohingya adolescents and youth in Bangladesh: a qualitative study. Research report. The Population Council, Inc, Dhaka, Bangladesh. 2018;17-22.

23. Uttom S, Rozario RR. Marriage in Malaysia lures Rohingya women. UCA news.com. 2019. https://www.ucanews.com/news/marriagein-malaysia-lures-rohingya-women/84563. Accessed14 July 2019.

24. Torkelsson A. The Plight of Women \& Young People in the Rohingya Refugee Crisis. Inter press service (IPS). 2018. http://www. ipsnews.net/2018/08/plight-women-youngpeople-rohingya-refugee-crisis/ Accessed 2 October 2019.

25. IASC Inter-Agency Standing Committee. IASC Guidelines for Integrating Gender-Based Violence InterventionsinHumanitarianAction, 2015.https://interagencystandingcommittee. org/working-group/documents-public/ iasc-guidelines-integrating-gender-basedviolence-interventions. Accessed 2 October 2019.

26. Montesanti SR. The role of structural and interpersonal violence in the lives of women: a conceptual shift in prevention of gender-based violence. BMC Women's Health 2015;15: 93. https://doi.org/10.1186/s12905-015-0247-5. Accessed 20 February 2020.

27. Nordby L. Gender-Based Violence in the Refugee Camps in Cox Bazar-A Case Study of Rohingya Women's and Girls' Exposure to Gender-Based Violence. Thesis, Uppsala Universitet. 2018.http://www.divaportal.org/ smash/get/diva2:1219686/FULLTEXT01. pdf. Accessed 2 October 2019.

28. United Nations (UN). Horrific accounts of sexual violence against Rohingya 'just tip of the iceberg' - UN agency. UN News. 2017b. https://news.un.org/en/story/2017/09/567342- horrific-accounts-sexual-violence-againstrohingya-just-tip-iceberg-un-agency. Accessed 2 October 2019.

29. IAWG. Inter-agency Working Group on Reproductive Health in Crises. Women and Girls Critically Underserved in the Rohingya Humanitarian Response. Relief web 2018. https://reliefweb.int/report/bangladesh/ women-and-girls-critically-underservedrohingya-humanitarian-response. Accessed 2 October 2019.

30. Human Rights Watch. "All my body was pain". Sexual violence against Rohingya women and girls in Burma. HRW.org. 2017. https://www.hrw.org/report/2017/11/16/allmy-body-was-pain/sexual-violence-againstrohingya-women-and-girls-burma. Accessed 2 October 2019.

31. Medecins Sans Frontieres (MSF). Three questions about sexual violence against Rohingya refugees. 2018a. https://www.msf.org/bangladesh-threequestions-about-sexual-violence-againstrohingya-refugees. Accessed 2 October 2019.

32. Medecins Sans Frontieres (MSF) "No One Was Left": Death and Violence against the Rohingya in Rakhine State, Myanmar. 2018b. https://www.doctorswithoutborders.ca/sites/ default/files/2018-03-no one was leftadvocacy_briefing_on mortality_surveys. pdf. Accessed 2 October 2019.

33. Farzana KF. Memories of Burmese Rohingya Refugees: Contested Identity and Belonging New York, NY: Palgrave Macmillan, 2017. p 103-106.https://doi.org/10.1057/978-1-13758360-4. Accessed 26 April 2020.

34. Hossain MM, Sultana A, Das A. Genderbased violence among Rohingya refugees in Bangladesh: A public health challenge. Indian Journal of Medical Ethics 2018b. DOI:10.20529/IJME.2018.045.

35. Wake C, Bryant J, HPG Working Paper. Capacity and Complementarity in the Rohingya Response in Bangladesh. 2018. https://www.odi.org/sites/odi.org.uk/files/ resource-documents/12554.pdf. Accessed 23 February 2020.

36. World Health Organization. Bangladesh: Rohingya Refugee Crisis 2017-2018, Public Health Situation Analysis. 2018. https://reliefweb.int/sites/reliefweb.int/files/ resources/public-health-situation-analysismay-2018.pdf. Accessed 29 July 2020. 
37. Huzairi S, Nada SZ, Khalilah AB, Shamsul B. Making the World a Better Place: Sharing Experiences at Malaysian Field Hospital, Bangladesh via Photos and Written Communication. International Journal of Human and Health Sciences. 2019; Supplementary Issue:51.

38. Ahmed Z, Ahmad A. Reclaiming fate of Rohingya Refugees: Role of Local and International NGO's. 2020.https://www. researchgate.net/publication/339106476 Reclaiming_fate_of_Rohingya_Refugees_ Role_of_Local_and_International_NGO's. Accessed 29 July 2020.

39. Huzairi S, Devananthan I. Permanent physical disfigurement and disability due to burns injury: Case series. International Journal of Human and Health Sciences 2020;4(4):319321.

40. Huzairi S, Nada SZ, Alias MY, Hasif N, Shamsul B. Patterns of Hospital Admission in 60 days at Malaysian Field Hospital in Bangladesh. International Journal of Human and Health Sciences. 2019; Supplementary Issue:35.

41. Myers A, Sami S, Onyango MA, Karki H, Anggraini R, Krause S. Facilitators and barriers in implementing the Minimum Initial
Services Package (MISP) for reproductive health in Nepal post-earthquake. Conflict and health 2018;12:35.

42. Women's Refugee Commission. Minimum Initial Service Package (MISP) for Reproductive Health in Crisis Situations: A Distance Learning Module. 2011.https://www. unhcr.org/4e8d6b3b14.pdf.Accessed14 July 2019.

43. Huang C, Schnabel L. Making Sexual and Reproductive Health Services a Priority for Rohingya Refugees and Host Communities. Reliefweb 2018.https://reliefweb.int/report/ bangladesh/making-sexual-and-reproductivehealth-services-priority-rohingya-refugeesand-host. Accessed 14.07.2019.

44. BhatiaA, Mahmud A, Fuller A, Shin R, Rahman A, Shatil T, et al. The Rohingya in Cox's Bazar: When the Stateless Seek Refuge. Health and Human Rights Journal 2018;20(2):105-122.

45. Shahabuddin M. Post-colonial Boundaries, International Law, and the Making of the Rohingya Crisis in Myanmar. Asian Journal of International Law 2019;9:334-358.

46. Karaman MI. Humanity's test with the refugee crisis (Editorial). Bangladesh Journal of Medical Science 2018;17(01):5-6. 